\title{
Mobile Augmented Reality based Learning System
}

\author{
Afsana $^{1}$, Hazra Shanuda Aeroshan ${ }^{2}$, Mr Manoj T ${ }^{3}$ \\ Student, Dept of CSE, Shri Madhwa Vadiraja Institute of Technology, Udupi, India ${ }^{1,2}$ \\ Assistant Professor, Dept of CSE, Shri Madhwa Vadiraja Institute of Technology, Udupi, India ${ }^{3}$
}

\begin{abstract}
Augmented Reality is a technology that allows the user to simultaneously see virtual and real information in a combined view blending the real world with the digital data. In this paper, we have specified about Mobile Augmented Reality in the field of education which will allow the experience of augmented reality without constraining the individual's whereabouts to a specific area. The implementation of this technique in rural areas will prove very beneficial to the students who cannot afford to spend a huge amount on education. This technology is new and also cost-effective and can bring the entire system of education in India to a new level.
\end{abstract}

Keywords: Augmented Reality, virtual, digital data, Mobile Augmented Reality.

\section{INTRODUCTION}

In today's world we are surrounded by technology all around us and they have transformed the way we live. We are completely dependent on the modern gadgets and use them on a regular basis. Even the classrooms are being upgraded to meet the requirements of the changing world. Tablets and internet are introduced to improve the quality of education. However, in a country like India considering the vast population, it is not possible to spend a huge amount of fund on education alone. Also, not every individual can afford to spend a lot on the fees in order to give their children smart learning in education.

Augmented reality aims to reduce these costs and provide smart learning experience for the students. Mobile Augmented Reality is a new technology which uses the existing environment and overlays new information on top of it. It integrates digital information with the user's environment in real time.

In other words, the system augments the image with digital data. AR embeds 3D graphics into a video in such a way as if the virtual elements were part of the real environment. This technique allows a user to explore interactively a virtual representation of video that is obtained from a real space. This has the effect of making a virtual world appear, to a limited extent, as the real world, while maintaining the flexibility of the virtual world.

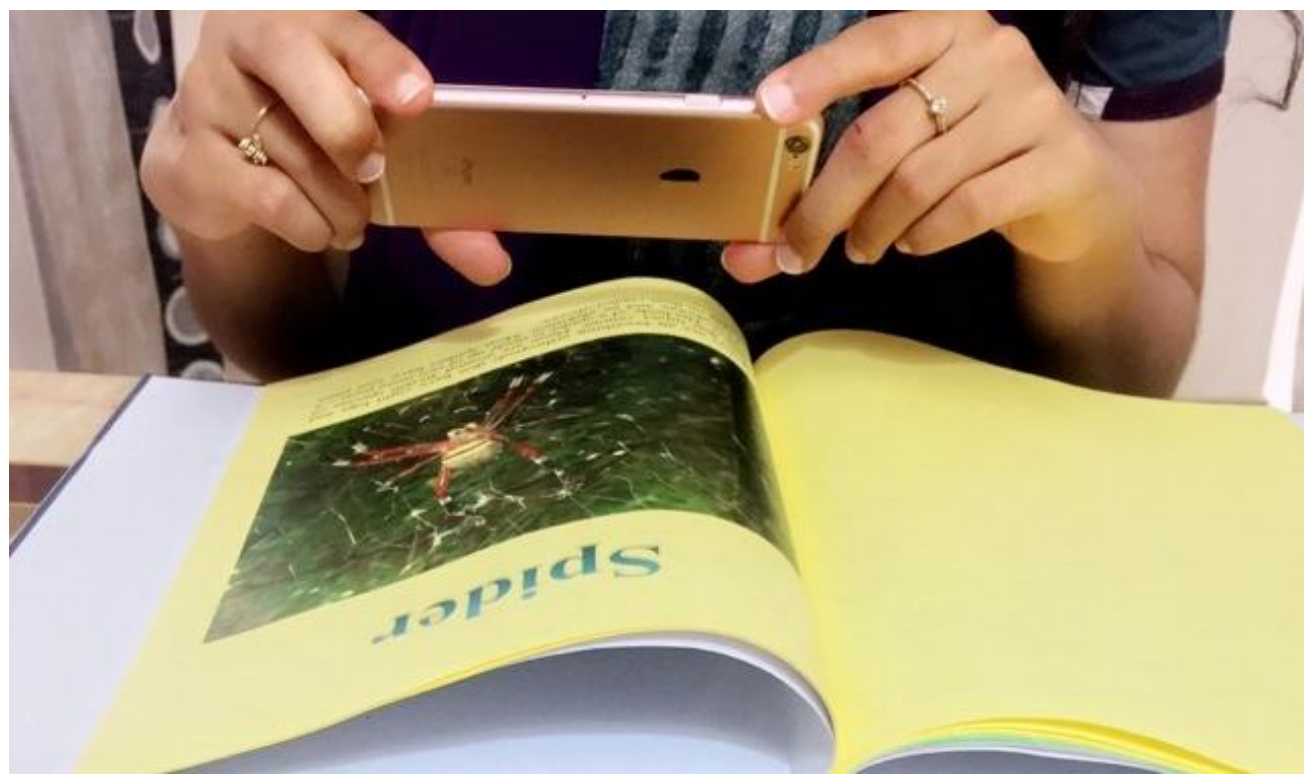

Fig: 1. User points phone's camera towards the image 


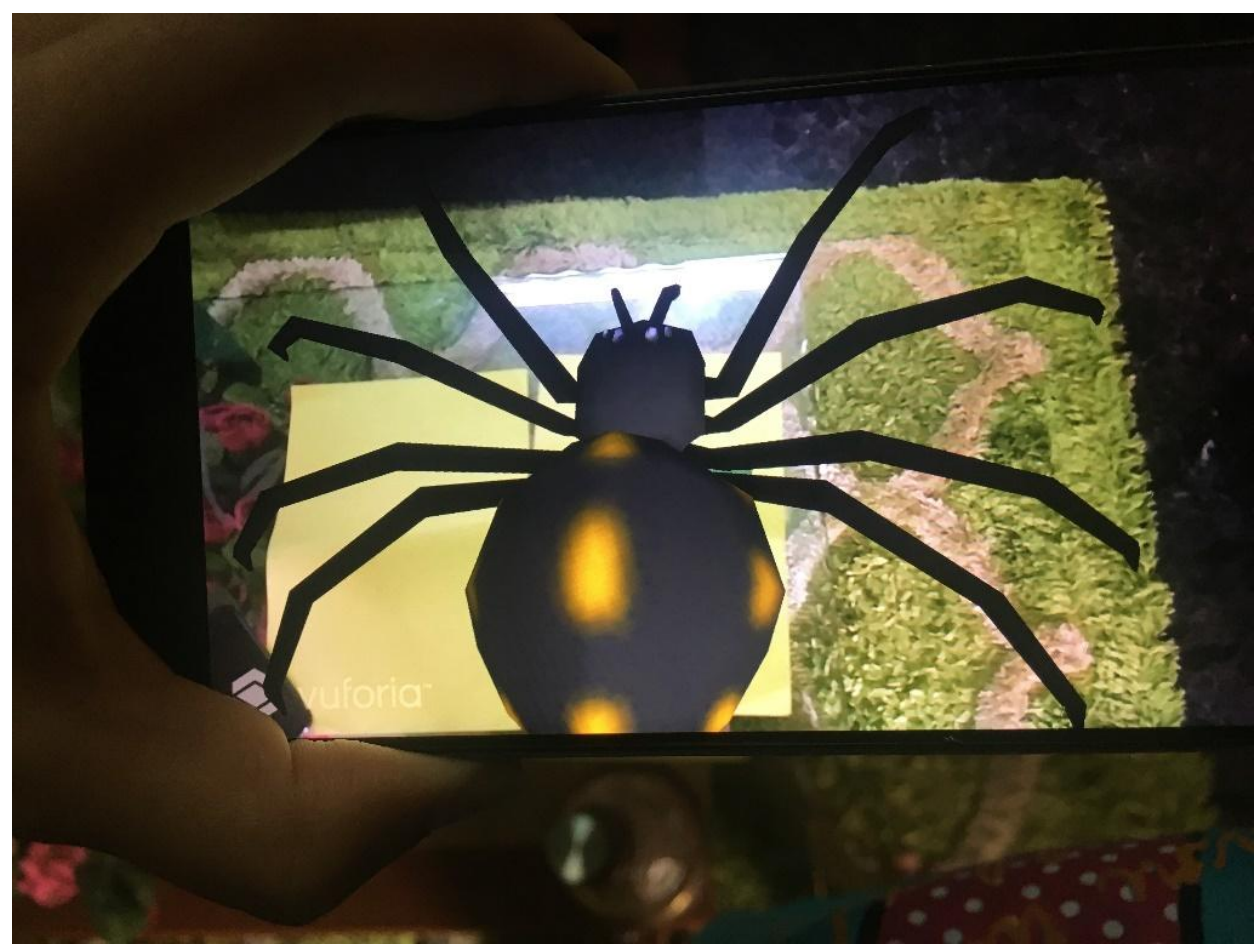

Fig 2. The image is detected and augmented image is displayed on the phone

Due to the development of the mobile devices, AR is growing rapidly and is becoming popular through in a variety of areas. Augmented reality has been in great demand and listed as the one among the few emerging technologies. Recent surveys say that Android is the most used mobile operating system for smartphones. By seeing the growing markets of smartphones, mobile learning seems to be the future of learning. Considering all these, our objective is to use the capabilities of augmented reality, Android and Mobility to build a mobile learning system which enhances learner's understanding with the aid of augmented reality based visualization technique.

AR also brings about an interactive experience, but aims to supplement the real world, rather than creating an entirely artificial environment. The physical objects in the individual's surroundings become the backdrop and target items for computer-generated annotations. Computer-presented material is directly integrated with the real world surrounding the freely roaming person, who can interact with it to display related information, to pose and resolve queries, and to collaborate with other people. The world becomes the user interface. The main purpose of the system is to develop an interface between the legacy book system and the digital information world. Books used in this system contain pages illustrated with pictures and description about them. We enhance the quality of Mobile Augmented Reality learning experience with the aid of Google VR Cardboard.

\section{LITERATURE REVIEW}

The students have been taught in the same way for years and there is a need to incorporate something new to meet the current day technology. In the elementary school classrooms, the current methodology of teaching is traditional and not upgraded, failing to produce interest in students. The traditional learning system cannot make the students visualise the concepts in 3-D structures and does not provide any interactions. Arranging for a physical model is not possible in every case and it will be too expensive. Also, Field trips have been an important part of education for many years. Unfortunately rising costs and falling revenues have caused many schools to eliminate extra expenditures of field trips.

Using AR, schools can either boost the educational value of providing a digital alternative, where an authentic field trip is not possible. AR provides the opportunity for students to be immersed in the learning experience from within a culturally-relevant perspective. The demand for software resources in recent years has grown more and more large.

In the past, augmented reality technology could only be used on the computer by the pixels of the webcam to enhance learning. But now with the aid of Mobile Augmented Reality, it can be applied in the mobile phone software where using the phone's camera, the entire learning system is moved to the next level. The phone is easy to carry; augmented reality is easy to generate more interactive applications no matter where you are. 


\section{III.SYSTEM ARCHITECTURE}

\section{A. 3D Object Creation Module:}

This module is included in set of 3D models, where all the 3D animal objects are created using the specific code written for each of the animals. This module gives input to "Augmented Reality Module" to load these 3D objects on top of the specially designed markers. This is also called as an overlaying of the virtual object on top of the marker which helps user to experience Augmented Reality based learning.

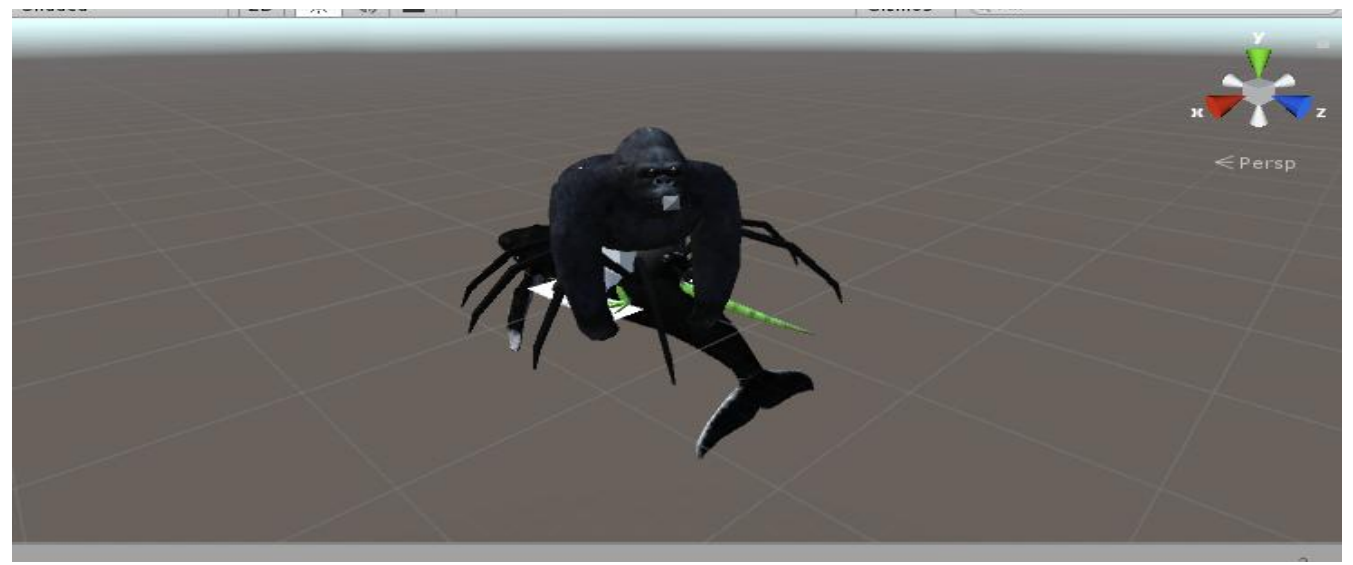

Fig 3 Creating 3-D Objects

\section{B. Augmented Reality Module:}

Image recognition for the book of the real-world marker which is being showed by the user is carried out in this module. This module helps in overlaying virtual 3D objects created. Ex: Overlaying of animal on top of the relevant image present in the specially designed Augmented Reality textbook. These 3D objects are created in 3D Object Creation Module.

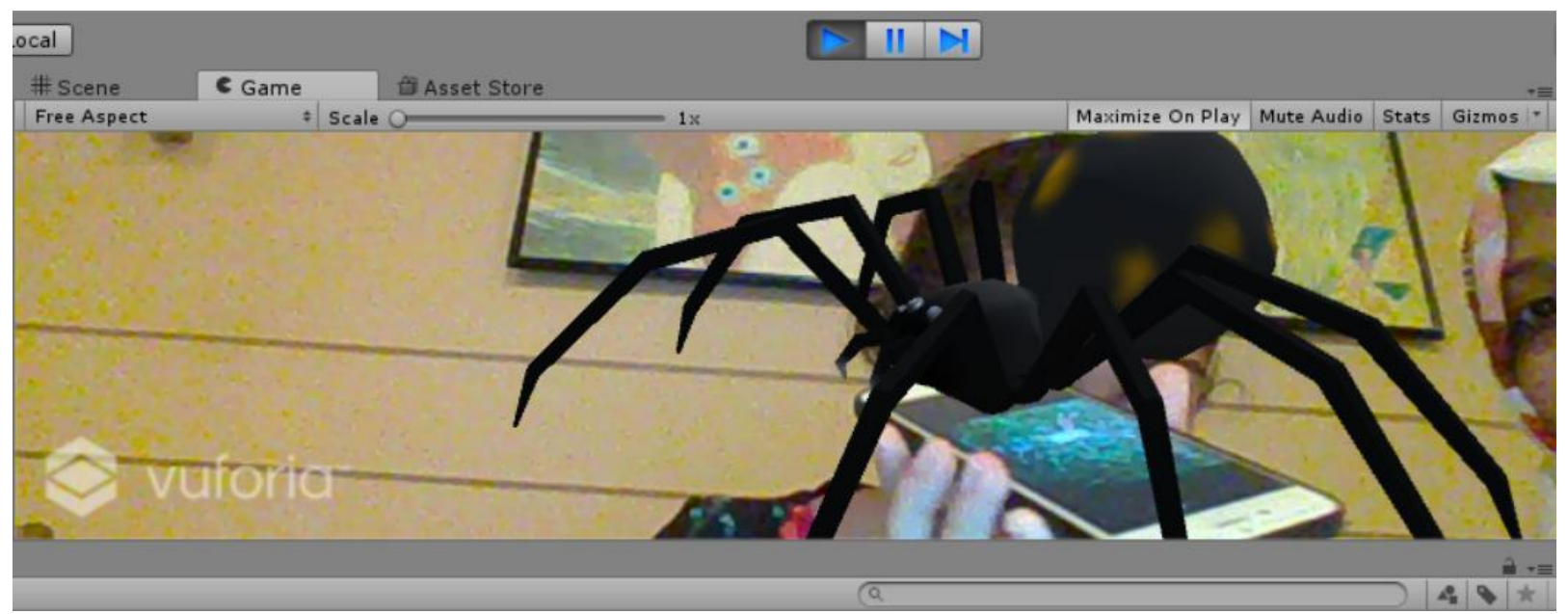

Fig 4. Augmented 3-D image overlayed

\section{IV.METHODOLOGY}

\section{A. Working Mechanism}

The student will have a copy of the book that the developers have worked on. The user needs to open the book and flip its pages. Whenever the student wishes to see the augmented 3-D image of the object present in the book, he/she needs to simply open the Augmented Reality application on his phone or tablet. The camera captures the real world. When the user points the camera towards the objects in the book, the image is analysed and checked for any matches. If the image has been previously registered, the image pattern will be immediately recognised. Input source is the book in which the images are embedded.

Interactive Mobile Augmented Reality Learning System application will be deployed in the smartphone system which contains an inbuilt. In the interactive book, the images are included in the book. When the book is bought under the 
camera, it uses image recognition technique to identify the pattern in the book. Once the image is recognized by the in the view finder of the app, the software converts that $3 \mathrm{D}$ object on to the image above the book using $3 \mathrm{D}$ rendering technique.

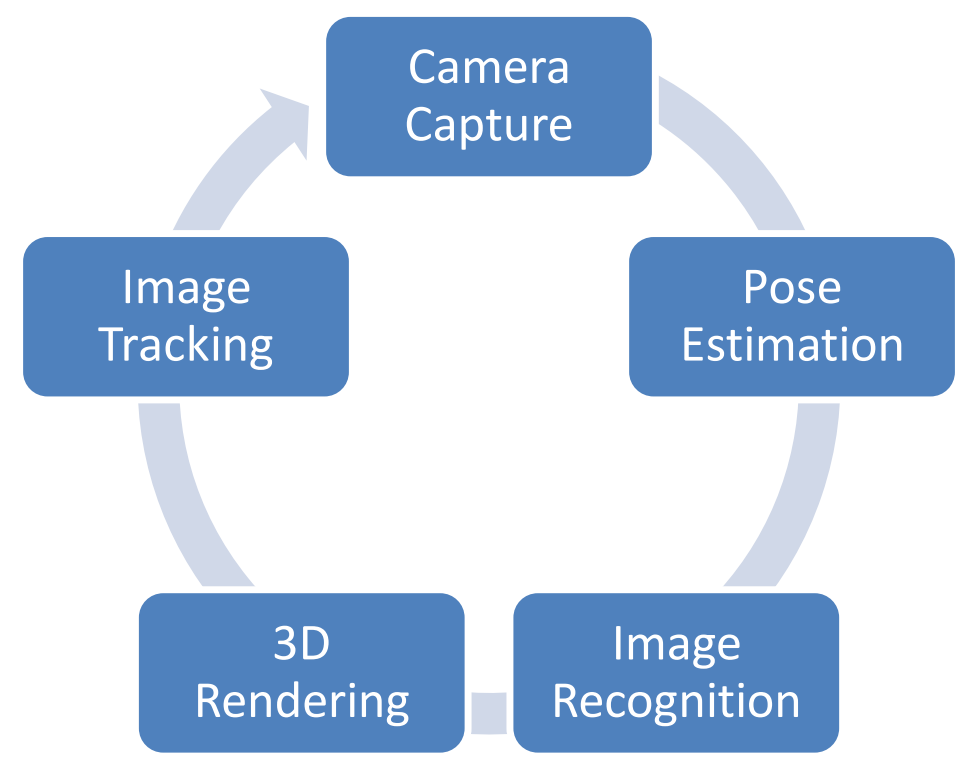

Figure 5. System process how MARLS works internally.

\section{B. Flow-Chart}

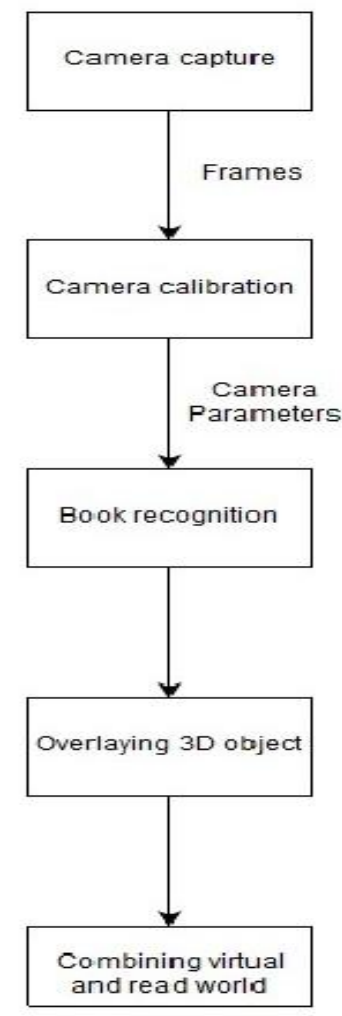

Fig 6. Flow chart showing working of Augmented Reality System

\section{RESULTS}

The purpose of this paper is to present the idea of bringing augmented reality into the field of education which could make the process of learning fun and interactive. A book with various 2-dimensional images is designed. An augmented reality learning system is developed. The learner is expected to install Mobile Augmented Reality 
application on a tablet or mobile having a webcam as one of its accessories. Whenever the phone's camera is pointed towards the book, the image is blended with the virtual image and an augmented image of the same will be displayed to the user.

During the course of time, when a flips over pages of the book, the system detects the images present on the page and overlays a 3D models such as Geometric Objects. Animals, Reptiles etc. on top of the relevant image present in the page. Learners are at liberty to rotate the 3D model by rotating the book. In this fashion, they could examine the entire periphery of the mammal, reptile, 3D geometry models or any other object for which the book is designed.

\section{VI.CONCLUSION}

Augmented Reality is very optimistic which suits the current growing technology trend. It can provide quality education to the student in cost-effective manner. Augmented Reality can be an integral part of active learning. This method of learning is interactive and prove to be beneficial especially for the students from the rural sector of India. It provides the opportunity for students to be immersed in the learning experience from within a culturally-relevant perspective. Mobile Augmented Reality based Learning system will be an initiative for advancement of education and contribute to the Prime Minister's digital India project.

\section{REFERENCES}

[1] "Mobile Augmented Reality" Tobias H. Höllerer Steven K. Feiner

[2] "Exploring MARS: developing indoor and outdoor user interfaces to a mobile augmented reality system." Höllerer, Tobias, et al.

[3] "Collaborative use of mobile augmented reality with paper maps." Morrison, Ann, et al.

[4] Bressler, D. M., and A. M. Bodzin. "A mixed methods assessment of students' flow experiences during a mobile augmented reality science game."Journal of Computer Assisted Learning 29.6 (2013): 505-517.

[5] Augmented Reality: Linking real and virtual worlds A new paradigm for interacting with computers Wendy E. Mackay Department of Computer Science Université de Paris-Sud ORSAY-CEDEX, FRANCE 